\title{
FREQUENCY OF TRANSFUSION TRANSMITTED DISEASES AMONG TRIBAL POPULATION OF RANGAMATI IN BANGLADESH
}

\author{
GOURAB DEWAN ${ }^{1}$, SARMISTA BISWAS $^{2}$, MD. RIDWANUR RAHMAN ${ }^{3}$
}

\begin{abstract}
Background: Frequency of transfusion transmitted diseases is unknown among tribal population of Rangamati. This study was undertaken to obtain data about burden of transfusion related diseases among tribal voluntary blood donors in Rangamati and to observe if there was any significant risk associated with ethnicity. The result expected to help identify health problems requiring urgent attention among tribal ethnic groups of Rangamati.
\end{abstract}

Methods: A retrospective study was done in Rangamati General Hospital, Bangladesh where screening records of tribal voluntary blood donors from year 2005 to 2012 were scrutinized for seropositivity for hepatitis $B \& C$, HIV, Syphilis and malaria infection. Frequency of these five diseases recorded.

Results: Ninety six (3.81\%) samples were positive for transfusion transmitted disease out of 2517 samples screened. Hepatitis B with 87 positive samples ranks highest. Frequency of seropositivity for HBsAg was $3.46 \%$. Seropositivity of other diseases was Hepatitis C (0.28\%), syphilis (0.04\%) and malaria (0.04\%). No samples were positive for HIV infection.

Conclusion: Hepatitis $B$ infection is the commonest transfusion transmitted disease among tribal population of Rangamati.

Key words: Transfusion transmitted disease, Tribal.

Received: 22 February 2014

Accepted: 19 June 2014

\section{Introduction}

Chittagong hill tract is an area vulnerable to disease outbreak. The various tribal groups living here cannot be dealt like the non-tribal general population because of socioeconomic \& cultural diversity. Health seeking behavior and practice among tribal groups differs from general population. ${ }^{1}$

Tribal health issue has emerged as an important health aspect in world. In Bangladesh this subject is still in infancy. Very few people know that a division in Directorate General of health Services(DGHS) of Bangladesh is working solely for tribal health from year 2012. Tribal/ethnic health has been given separate importance under current Health, Population and Nutrition Sector Development Program(HPNDSP) program of country. ${ }^{2}$ Ministry of Health of Government of Bangladesh (GOB) recognizes lack of data regarding different health issues among tribal population hindering development of policy. ${ }^{2}$

Arranging blood transfusion free of Transfusion transmitted diseases (TTD's) has long been important healthcare issue in Bangladesh. Under safe blood transfusion act all government facilities routinely carry out screening for hepatitis B virus (HBV), hepatitis $\mathrm{C}$ virus (HCV), human immunodeficiency virus (HIV), veneral diseases and malaria parasite in donor's blood. As small step to develop data on various health issues concerning tribal people we decided to estimate frequency of TTD's among tribal blood donors in the district of Rangamati.

Prior studies in Bangladesh were done either in Medical College Hospitals, Bangabandhu Sheikh Mujib Medical University (BSMMU) or private blood donating organization. ${ }^{3-6}$ We could find only one study done outside Dhaka city as reference. ${ }^{7}$ Study population varied from voluntary donors to specific high risk groups ie. Professional donors. The population of these studies consisted of nontribal general population. Therefore we decided to analyze this issue from a district (Rangamati) hospital perspective where unique cultural characteristic allowed us to observe frequency of TTD's among population with separate anthropological background.

\section{Materials and Methods:}

A retrospective study carried out in Rangamati General Hospital. According to national policy

1. Consultant, Medicine, Rangamati General Hospital, Rangamati.

2. Assistant Professor, Medicine, Dhaka Medical College, Dhaka.

3. Professor, Medicine, Shaheed Suhrawardi Medical College, Dhaka.

Bangladesh J Medicine 2014; 25 : 52-54 
hepatitis $\mathrm{B}$, hepatitis $\mathrm{C}$, HIV, veneral disease research laboratory (VDRL) serology and test for malaria parasite routinely carried out before blood trsnfusion. We scrutinized record registers of blood sample screened in past years. Data collected from the year 2005 (21 $1^{\text {st }}$ August) to 2012 (31 ${ }^{\text {st }}$ December). Each year's data for individual donor of tribal origin was examined and the frequency of TTD's recorded. Non-tribal donors were excluded.

All serological tests were performed using screening kits supplied by National Safe Blood Transfusion Program (NSBTP) under GOB.HBV,HCV and HIV was detected using immunochromatographic (ICT) method. Malaria parasite detection under microscope carried out using traditional slide method after staining with Giemsa stain. Macroscopic nontreponemal flocculation test method was used in VDRL test to detectanticardiolipin antibody.

Data analyzed in SPSS version 17. Frequency of various TTD was recorded.

\section{Results:}

From a total of 4535 people screened;2517 (55.5\%) were of tribal background. Tribal male donors were $2369(94.12 \%)$ and female donors were 148 (5.88\%). Blood donors were representative from ten different tribal groups. Chakma community had the highest representation $(n=2250)$. Mean age of population studied was $26.83 \pm 6.56$ years. The age, sex, ethnic characteristics of the population given in table-I.

\section{Table-I}

Age, sex and ethnic distribution of population

\begin{tabular}{lcccc}
\hline Tribal group & $\begin{array}{c}\text { Total } \\
\text { population }\end{array}$ & Male & Female & Mean age \\
\hline Chakma & 2250 & 2121 & 129 & $26.78 \pm 6.80$ \\
Marma & 102 & 100 & 2 & $26.92 \pm 7.11$ \\
Tripura & 91 & 87 & 4 & $27.70 \pm 6.31$ \\
Tanchangya & 54 & 46 & 8 & $28.00 \pm 9.32$ \\
Gurkha & 7 & 5 & 2 & $30.71 \pm 2.87$ \\
Pankhua & 6 & 5 & 1 & $29.83 \pm 6.70$ \\
Assam & 4 & 4 & - & $25.00 \pm 4.24$ \\
Others & 3 & 1 & 2 & $20.50 \pm 0.70$ \\
\hline Total (N) & 2517 & 2369 & 148 & $26.83 \pm 6.56$ \\
\hline
\end{tabular}

Ninety six (3.81\%) units of blood tested seropositive for different TTD's. Among positive cases 92 (95.83\%) were male and $4(4.17 \%)$ were female. HBV seropositive cases were highest in number $(n=87)$. Hepatitis $\mathrm{C}$ positive and VDRL reactive cases were 7 and 1 in number respectively. Surprisingly despite Rangamati being one of the most endemic districts; only one blood sample was positive for malaria parasite (Table-II). No sample was positive for HIV infection.

Table-II

Distribution of transfusion transmitted diseases by tribal ethnicity

\begin{tabular}{lccccccccc}
\hline Name of test & $\begin{array}{c}\text { Chakma } \\
\mathrm{n}=87\end{array}$ & $\begin{array}{c}\text { Marma } \\
\mathrm{n}=2\end{array}$ & \multicolumn{2}{c}{$\begin{array}{c}\text { Tripura Tanch- } \\
\mathrm{n}=2\end{array}$} \\
& $\mathrm{M}$ & $\mathrm{F}$ & $\mathrm{M}$ & $\mathrm{F}$ & $\mathrm{M}$ & $\mathrm{F}$ & $\begin{array}{c}\text { M } \\
\text { angya }\end{array}$ & Total \\
\hline HBsAg +Ve & 77 & 3 & 1 & - & 2 & - & 3 & 1 & 87 \\
$\mathrm{HCV}+\mathrm{Ve}$ & 5 & - & 1 & - & - & - & 1 & - & 7 \\
$\mathrm{VDRL}$ reactive & 1 & - & - & - & - & - & - & - & 1 \\
$\mathrm{MP}+\mathrm{Ve}$ & 1 & - & - & - & - & - & - & - & 1 \\
$\mathrm{HIV}+\mathrm{Ve}$ & - & - & - & - & - & - & - & - & - \\
\hline Total $(\mathrm{N})$ & 84 & 3 & 2 & - & 2 & - & 4 & 1 & 96 \\
\hline
\end{tabular}

Frequency of different TTD's among tribalswere HBV (3.46\%), HCV $(0.28 \%)$, Syphilis $(0.04 \%)$ and malaria (0.04\%).

\section{Discussion:}

High frequency (90.6\%) of HBsAg seropositivity ( $\mathrm{n}=87$ ) observed among all detected TTD $(n=96)$ in our study was consistent with the result of studies done in several tertiary level hospitals of Bangladesh. ${ }^{5-7} \mathrm{HBV}$ infection is the commonest TTD in our country as per record. 8

National data of Bangladesh show a seroprevelance of $0.96 \%$ for HBsAg among blood donors. ${ }^{8}$ In three Medical College Hospitals HBV prevalence was slightly higher(1.38 to $2.19 \%) .{ }^{5-7}$ These mentioned studied were done among general bengali population.In Rangamati with 3.46\% HBsAg seropositivityamong tribal population the prevalence was higher than the mentioned data.

Ethnic difference can influence HBV seroprevalence. A study in Indonesia found that Chinese background increased risk of HBV infection by three fold than Malayan ethnicity. ${ }^{9}$ In United Kingdom higher prevalence of HBV was observed in blood of African, Pakistani and non-British white women(migrated population) in antenatal visit compared to native British women. ${ }^{10} \mathrm{Akbar}$ et al. concluded that variable immunologic response in different ethnic groups to HBV infection determined final scenario. ${ }^{9}$ In northern Thailand HBV and HCV seroprevalence among seven minorities (Lahu, Lisu, Shan, Red Karen, White 
Karen, Hmong and Akha) was estimated. Study found HBV prevalence was significantly different by groups $(\mathrm{P}<0.05)$ but that of HCV was not. ${ }^{11}$ Because of cultural diversity various important risk factors for HBV transmission like IV drug abuse, practice of sexual promiscuity are not common among the tribal population of Rangamati so possibility of transplacental infection is high. Transplacental infection is the commonest route of transmission in Bangladeshi asymptomatic HBV carriers. ${ }^{12}$

$\mathrm{HCV}$, Syphilis frequency was low in Rangamati. This observed result is similar to separate studies done in Bangladesh. ${ }^{3-7}$ Hepatitis $\mathrm{C}$ prevalence in five native studies ranged from 0.024 to $0.52 \%{ }^{3-7}$ Present study result for $\mathrm{HCV}$ was $0.28 \%$. National data for HIV positive cases among blood donors is $0.0065 \% .{ }^{8}$ In Sir Salimullah\& Khulna Medical College Hospital the prevalence was $0.06 \%$ and $0.006 \%$ respectively. ${ }^{6-7}$ But in Rangamati no tribal people were positive for this dreadful disease.

Malaria parasite detection rate $(0.04 \%)$ was lower in comparison to the studies done in non-endemic areas of Bangladesh. In two studies in Dhaka parasite detection rate was $0.11(n=21448)$ and $0.76 \%(n=400)$ respectively. ${ }^{4-5}$ While two large scale studies collectively consisting of 34236 subjects demonstrated no parasite. ${ }^{6-7}$ This low parasite detection rate may be due to decline in malaria endemicity in this district.

\section{Conclusion:}

The burden of HBV infection is high among tribal voluntary blood donors of Rangamati. A community based epidemiological study can be considered to estimate the actual burden and underlying risk factors in this community.

Funding: None.

Conflict of interest: None.

\section{References:}

1. Rahman SA, Kielmann T, McPake B, Normand C. $\mathrm{J}$ Healthcare-seeking Behaviour among the Tribal People of Bangladesh: Can the Current Health System Really Meet Their Needs? J Health Popul Nutr. 2012 Sep; 30(3):353-365

2. Bangladesh.Ministry of Health \& Family Welfare.Tribal/Ethnic Health Population and Nutrition Plan for the Health, Population and
Nutrition Sector Development Program (HPNSDP) 2011 to 2016. Dhaka: 2011.

3. Habibullah $\mathrm{M}$ M, Khatun $\mathrm{H}$, Khatun A, Rabbi FJ.Seroprevalance of anti-HCV among voluntary blood donors. Bangladesh J Med Microbiol. 2009; 03 (01): 37-39

4. Hoque MM, Islam MA, Begum HA, Rahman M, Rahman SM, Al Mamun MA et al. Prevalence of Malaria Parasites Among Blood Donors In Selected Hospitals of Dhaka City. J Dhaka Med Coll.2008 October; 17 (2): 94-97

5. Chowdhury FS, Begum HA, Adnan SD, Hoque MM, Hossain MZ, Siddiqui MAE.Study on Screening Tests Among The Blood Donors InDhaka Medical CollegeHospital, Bangladesh. J Dhaka Med Coll. 2010; 19(1): 16-18.

6. Saha SK, Banik RK, Saha MR, Habibullah MM, AlMahtabM.Prevalence of Transfusion Transmitted Infection in Healthy Blood Donors in Sir SalimullahMedical College Dhaka, Bangladesh. Euroasian Journal of Hepato-Gastroenterology. 2011; 1(2): 68-70.

7. Ahmed MU, Begum HA, Hossain T, Chakraborty P. Incidence of Common Transfusion TransmittedDiseases Among BloodDonors.JAFMC Bangladesh. 2009 June; 5 (1): 4-6

8. Safe Blood Transfusion Center.Annual reports of donor screening, DMCH, Dhaka. 2009

9. Akbar N, Basu B,Mulyanto T, Garabrant DH,Sulaiman A,Noer HMS.Ethnicity, Socioeconomic status,transfusions and risk of hepatitis Band hepatitis $\mathrm{C}$ infection.J Gastroenterol and Hepatol.1997;12:752-751

10. Caley M, Fowler T, Greatrex S, Wood A.Differences in hepatitis $\mathrm{B}$ infection rate between ethnic groups in antenatal women in Birmingham, United Kingdom, May 2004 to December 2008 . [Online]. Available from: http://www.eurosurveillance.org/ ViewArticle. aspx?ArticleId $=20228$

11. Ishida $\mathrm{T}$, Takao $\mathrm{S}$, Settheetham-Ishida $\mathrm{W}$, Tiwawech D. Prevalence of hepatitis $B$ and $C$ virus infection in rural ethnic populations of Northern Thailand. J ClinVirol. 2002 Feb;24(1-2):31-5.

12. Harun-or-Rashid, Alim A, Ekram ARMS, Mahmood I, Hoque MM, Rahman K et al. Vertical Transmission of Hepatitis B Virus is the most Important Route of Transmission in Asymptomatic Carriers in Bangladesh .Teachers Association Journal. 2009; 22 (1): 97-100. 